http://dx.doi.org/10.21707/gs.v10.n01a18

\title{
CULTURA E NATUREZA NO PENSAMENTO ANTROPOlÓGico: DO DEBATE EPISTEMOLÓGICO À PESQUISA COM UMA POPULAÇÃO LOCAL ${ }^{1}$
}

\author{
Maristela Oliveira de Andrade ${ }^{2}$ \& Jeandelynne A. A. Sampaio ${ }^{3}$
}

\begin{abstract}
${ }^{1}$ Os dados empíricos deste artigo foram extraídos da pesquisa oriunda da dissertação da segunda autora sob a orientação da primeira intitulada " $A$ carcinicultura familiar na aldeia indígena potiguara de Tramataia, Marcação/ Paraíba: em busca da sustentabilidade”, Programa de Pós-Graduação em Desenvolvimento e Meio Ambiente /UFPB, 2015

${ }^{2}$ Titular Prodema e PPGA-UFPB, coordenadora do Grupo Interdisciplinar de Pesquisa em Cultura, Sociedade e Ambiente. E-mail: andrademaristela@hotmail.com

${ }^{3}$ Mestre em Desenvolvimento e Meio Ambiente Prodema-UFPB, Gerente do Dicoco Agroindustrial LTDA Brasil. E-mail:jeandelynnejeandel@gmail.com
\end{abstract}

Recebido em 30 de novembro de 2015. Aceito em 30 de março de 2016. Publicado em junho de 2016.

\begin{abstract}
Resuмo - Este artigo propõe uma reflexão teórica sobre o pensamento antropológico em sua contribuição aos estudos em torno da relação entre cultura e natureza, sob três perspectivas teóricas: a antropologia ecológica, o estruturalismo francês e a antropologia da natureza. A análise teve inicialmente como eixo a identificação das propostas de cada vertente teórica de superação da separação entre cultura e natureza estabelecida pela ciência moderna. Em seguida, as reflexões se voltaram para o campo empírico, para considerar as relações entre cultura e natureza vividas por uma população local. A pesquisa em foco se refere a um grupo indígena que vivenciou mudanças recentes com a introdução da criação de camarão em viveiro, substituindo o extrativismo pesqueiro pelo cultivo, provocando na prática uma alteração na relação cultura e natureza. Do diálogo entre as dimensões teórica e empírica observou-se que a superação da separação entre cultura e natureza defendida pelos teóricos pesquisados foi baseada em realidades empíricas que diferem daquela aqui pesquisada, já que a separação tem persistido em função da modernização experimentada pela população local investigada.
\end{abstract}

Palavras-Chave: Cultura e natureza; Antropologia ecológica; Antropologia da natureza

THE RELATIONSHIP BETWEEN CULTURE AND NATURE ACCORDING TO ANTHROPOLOGICAL THINKING: FROM EPISTEMOLOGICAL DEBATE TO RESEARCH INVOLVING A LOCAL POPULATION

Aвstract - This article proposes a theoretical reflection on the anthropological thinking concerning the relationship between culture and nature - a reflection constructed from three theoretical perspectives: ecological anthropology, French structuralism and the anthropology of nature. The analysis was initially centered on the identification of the ideas characterizing these three perspectives, which have sought to eliminate the separation between culture and nature established by modern science. Then, it turned to the empirical field to examine the relationships between culture and nature experienced by a local population: an indigenous group that has recently underwent changes resulting from the adoption of shrimp farming in substitution for traditional fishing, which has altered the relationship between culture and nature. The dialogue between theory and practice has shown that the elimination of the mentioned separation by theorists has been based in situations that differ from the one studied here since this separation has been present in the modernization (the adoption of shrimp farming) experienced by the local group in question.

KeY WoRDs: Culture and nature; Ecological anthropology; Anthropology of nature

\section{CULTURA Y NATURALEZA EM ANTROPOlOGÍA: DEL DEBATE EPISTEMOLÓGICO A LA INVESTIGACIÓN CON UNA POBLACIÓN LOCAL}

Resumen - Este artículo propone una reflexión teórica sobre el pensamiento antropológico en su contribución a los estudios sobre la relación entre la cultura y la naturaleza, bajo tres perspectivas teóricas: Antropología ecológica, el estructuralismo francés y la antropología de la naturaleza. El análisis tuvo inicialmente como la identificación de propuestas de cada filamento que establece la separación teórica entre cultura y naturaleza por la ciencia moderna. A continuación, los pensamientos se han convertido en el campo empírico, a considerar las relaciones entre cultura y naturaleza experimentada por una población. Investigación en el enfoque se refiere a un grupo indígena que experimenta cambios recientes con la introducción de la creación del camarón en viveiro, sustitución de las actividades extractivas de pesca por cultivo, dando por resultado un cambio en la relación entre cultura y naturaleza. Diálogo entre las dimensiones empíricas y teóricas señaló superar la separación entre cultura y naturaleza propugnado por teóricos de la encuesta se basó en realidades empíricas difieren de que aquí, puesto que la separación ha persistido en la función de modernización experimentada por la población local.

Palabras Clave: Cultura y naturaliza, Antropologia ecológica, Antropologia de la naturaleza

\section{INTRODUÇ̃̃o}

A polaridade entre cultura e natureza tem persistido como modelo classificatório para ordenar o mundo, se expressando como problema epistemológico. Para a antropologia pode-se dizer que o debate sobre as fronteiras entre cultura e natureza foi iniciado desde as origens da formação da disciplina, sendo dominado por critérios filosóficos, inspirados em Rousseau, Hobbes, Montesquieu entre outros. Porém por serem dominados por um sentido moral, eles foram mais tarde substituídos por critérios ecológicos. No final do século XX com a inserção da antropologia no debate sobre a crise ambiental, foram agregados critérios políticos à discussão filosófica e ecológica. O presente trabalho propõe um percurso teórico e crítico sobre a construção epistemológica da relação entre cultura e natureza no campo do pensamento antropológico, para em seguida tentar articular com dados fornecidos por experiências vividas em contextos de populações locais.

A escrita deste artigo foi motivada pelos debates propiciados pela disciplina Cultura e Ambiente lecionada pela primeira autora para turmas do bacharelado em ciências sociais e do mestrado em antropologia (PPGA) da Universidade Federal da Paraíba - UFPB. O programa da disciplina foi construído em torno do tema das fronteiras entre cultura e natureza, e nas tentativas de superação dessas fronteiras por alguns teóricos mais recentes. Como integrantes do Programa de Pós-Graduação em Desenvolvimento e Meio Ambiente da UFPB, as autoras dialogam com uma equipe multidisciplinar composta de docentes de variadas formações e se defrontam com experiências de pesquisa com problemáticas que se situam nas relações entre cultura e natureza (Andrade e Lima, 2012). Com isso, a discussão teórica e epistemológica ensejou reflexões a partir de alguns exemplos destas experiências de pesquisa. Contudo, a pesquisa que serviu de referencia para esta análise foi realizada pela segunda autora envolvendo um grupo indígena, cujo território contém uma sobreposição com uma Área de Proteção Ambiental, na qual os indígenas desenvolvem um cultivo de camarão em viveiro em escala familiar. 
Considerando que a relação entre cultura e natureza constitui para antropologia uma questão permanente, foi necessário delimitar o campo da análise, identificando as contribuições teóricas no âmbito da literatura antropológica, para nortear este percurso teórico. Outros critérios foram elencados para ordenar o debate proposto, entre eles o comprometimento dos teóricos com a problemática envolvendo o campo ecológico e ambiental. Foram selecionadas três abordagens antropológicas, mais comprometidas com o tema em pauta: a antropologia ecológica; o estruturalismo francês e a antropologia da natureza, finalizando com uma rápida incursão na ecologia política. Neste sentido, as vertentes escolhidas evocam três esferas cruciais que envolvem as interrelações entre cultura e natureza, sendo elas respectivamente a esfera do econômico, do simbólico e da política.

Assim, o problema epistemológico da relação entre cultura e natureza assume orientações distintas, conforme as premissas de cada vertente teórica e a trajetória dos estudos empíricos produzidos no âmbito de cada uma, como se tentará analisar ao longo deste trabalho.

Portanto, o traço comum é o reconhecimento do papel desempenhado pela esfera ambiental ou ecológica para a compreensão dos processos sociais. De um lado se situam as chamadas culturas tradicionais, que têm uma relação mais estreita com a natureza, de onde retiram seu sustento, e do outro lado, as culturas contemporâneas através dos movimentos ambientalistas, que buscam reencontrar uma relação perdida com a natureza. Em ambas as realidades temporais e espaciais ocorreriam formas de superação desta polaridade, embora ela de fato ainda persista tendo em vista a continuidade da racionalidade moderna ocidental.

A antropologia da natureza concebida por Descola (2007) se aproximou do estruturalismo ao destacar as relações tensas entre cultura e natureza no âmbito das cosmologias e mitologias indígenas. Já Latour (2004) se filia à antropologia da natureza para analisar a possibilidade de aproximação entre a natureza, a ciência e a política através de um diálogo entre políticos e cientistas, onde a política e a natureza se fundem. Esse diálogo é tenso em virtude das controvérsias entre especialistas da natureza e políticos compondo duas câmaras a dos especialistas defensores da conservação da natureza e a dos políticos referente aos interesses dos humanos. A tendência é a formação de uma assembleia única para exercer uma política da natureza.

Contudo, para ecologia política a exploração intensiva da natureza pelos grandes capitalistas deve ser distinguida da produção em pequena escala de populações locais, considerando os desequilíbrios distributivos em relação ao uso dos recursos naturais (Little, 2006; Alier, 2009). Entretanto, Foladori e Taks (2004) filiados à antropologia ecológica, numa visão crítica mais recente consideram que a "sabedoria ecológica dos primitivos", deveria ser reavaliada, cabendo à antropologia o papel de "desmistificar os preconceitos sobre a relação das sociedades com seus ambientes naturais" e o de "abordar os problemas ambientais de modo a caminhar rumo a sociedades mais sustentáveis” (Foladori e Taks, 2004). Há inúmeros exemplos de colapsos ambientais com o desaparecimento de culturas inteiras provocados pela desertificação de grandes áreas, pelo modo insustentável de exploração dos recursos naturais por paleoíndios ou civilizações desaparecidas (Diamond, 2012). Tais exemplos demonstram que as sociedades tradicionais não têm um modo de vida em equilíbrio com a natureza, sendo a busca de uma relação mais equilibrada um projeto em construção nas sociedades contemporâneas.

Neste sentido, a pesquisa escolhida para dialogar com esses autores oferece um exemplo desta posição da antropologia, em que um grupo indígena que integra a categoria de povos tradicionais, passa a desenvolver a carcinicultura como sistema produtivo local, que reconhecidamente provoca degradação ambiental com desmatamento e perda de biodiversidade. Esta inovação tecnológica engendra uma nova forma de relação cultura e natureza para este segmento da população indígena.

Para iniciar a análise será exposto um quadro teórico metodológico de cada vertente selecionada, inserindo em cada uma o debate epistemológico que emergiu das reflexões dos diferentes antropólogos filiados a elas.

\section{A POLARIDADE ENTRE CULTURA E NATUREZA NA ANTROPOLOGIA ECOLÓGICA}

A antropologia ecológica se situa no marco da tradição norte-americana que introduziu de forma sistemática a variável ambiental nos estudos antropológicos, dentro de uma matriz teórica fundada no neoevolucionismo e no materialismo cultural, que privilegia a dimensão econômica. Uma parcela significativa de antropólogos norte-americanos foram formados sob a influencia dos estudos de J.Steward e L.White entre as décadas de 1930 a 1980. Entretanto, alguns deles como Rappaport (1984) se afastaram da visão neoevolucionista dos fundadores para investir numa teoria neofuncionalista, e introduziram o conceito biológico de ecossistema, com suas propriedades - o holismo e a capacidade de auto-regulação interna - como geradoras de homeostase ou equilíbrio dinâmico. Ao adotarem a população local como unidade de estudo, a cultura passou a ser concebida como instrumental e como mecanismo adaptativo, que se ajusta ao processo de regulação do ambiente ou ecossistema, no qual ela está inserida (Neves, 1996; Adams, 2000).

Cabe destacar outras premissas da matriz teórica da antropologia ecológica, em que a adaptação de populações humanas a determinados ambientes assume papel central, cuja relação dinâmica é influenciada pelo fluxo de energia que inclui as práticas de exploração dos recursos disponíveis para o aproveitamento em sua dieta alimentar, representada pela eficiência no consumo proteico ou energético dessas populações.

Já Marvin Harris (2011) e Sahlins (1979) seguiram algumas tendências da escola, mas enveredaram por caminhos opostos. Se o primeiro consolidou o fundamento do materialismo cultural em seu estudo sobre a racionalidade econômica e energética da interdição religiosa do consumo de proteína oriunda da vaca pelos indianos, o segundo rompe com esta tradição ao produzir uma crítica contundente ao materialismo, especialmente à visão utilitarista, com sua tese da afluência das comunidades de caçadores e coletores do paleolítico (Sahlins, 1978).

A crítica de Sahlins em Cultura e Razão Prática se orienta para a rejeição de duas concepções materialistas da cultura, seja a do tipo naturalístico, que concebe a economia como "manutenção da população humana dentro de limites de viabilidade biológica” (Sahlins, 1979); seja a do tipo utilitarista, em que o processo produtivo se traduz como forma de subsistência que exclui sua dimensão histórica. Para este autor a dimensão material do trabalho e as práticas correspondentes existem de forma articulada a uma ordem cultural ou simbólica. Assim, Sahlins ao propor romper a dicotomia entre a parte material e a racional ou simbólica da cultura, para construir uma visão integrada através da noção de razão prática, investe seu esforço em trazer a antropologia de volta para sua premissa fundadora de compreensão da cultura com sua propriedade de intervenção na natureza.

O debate das fronteiras entre cultura e natureza foi intenso nesta corrente, tendo provocado uma espécie de ruptura entre os antropólogos que mantiveram-se no lado da cultura como Steward, White, e os que escolheram construir suas análises mantendo-se 
no lado da natureza, através da adoção do conceito de ecossistema. Nesta perspectiva analítica, o humano e a cultura perdem a posição de centralidade com a emergência do meio envolvente, ou seja, o ambiente ou o ecossistema, para autores como Rappaport (1984). Para eles, a cultura passa a ser tão somente uma propriedade ou atributo da população humana nos processos adaptativos em suas interações com as outras espécies bióticas e as abióticas no ecossistema contribuindo para homeostase. A opção por realizar pesquisas situadas neste espaço de fronteira impôs, portanto, uma escolha pela operacionalização do conceito de cultura ou de natureza ou ecossistema, emergindo daí a pergunta sobre qual dessas esferas deveria ser privilegiada ou determinante.

Desta forma, o problema epistemológico da fronteira no âmbito desta tradição antropológica se configurou pela oscilação entre a adesão ao polo da cultura ou ao polo da natureza, sem que os representantes da antropologia ecológica tenham chegado a um consenso. Para os partidários da ecologia cultural, a antropologia deveria permanecer fiel aos estudos sobre cultura, mantendose alinhados com o culturalismo, enquanto os da ecologia humana sentiam-se à vontade para transitar para o polo da natureza analisando os processos sociais como paralelos ou similares aos processos naturais.

Nesta etapa do debate epistemológico, o que está em pauta é a reafirmação da dicotomia entre cultura e natureza e não a sua superação, uma vez que a polêmica é construída em torno da escolha do eixo dominante da análise.

\section{O PROBLEMA EPISTEMOLÓGICO DA RELAÇÃO CULTURA E NATUREZA NO ESTRUTURALISMO FRANCÊS E NA ANTROPOLOGIA \\ DA NATUREZA}

O ponto de ruptura entre a tradição antropológica norteamericana e a francesa poderia ser indicado simplificadamente através da adoção do critério baseado na dicotomia entre a dimensão material e simbólica da cultura. Partindo da classificação de Neves (1996) a tradição norte-americana seria rotulada de antropologia da "barriga", e a francesa de antropologia da "pensée" embora LéviStrauss tenha reagido a seus colegas anglo-saxões quanto ao rótulo de idealista/intelectualista. Em vários de seus livros, entre os quais O cru e o cozido (1991), O olhar distanciado (2010), De perto e de longe (2005), Lévi-Strauss reage ao rótulo e reitera que fez uso de critérios extraídos da história e da especificidade do habitat dos grupos indígenas detentores dos mitos coletados na construção de suas análises.

Assim, ele defende que a antropologia é antes de tudo uma ciência empírica, de modo que o estudo do mito deve estar fundamentado na relação entre cultura e meio ambiente. Para assegurar a relação entre os mitos indígenas e a natureza, fez questão de informar que durante a realização de sua investigação, muniu-se de uma literatura com inventários e classificações de espécies da botânica e da zoologia. Partindo dela se deteve na identificação de plantas e animais conhecidos e empregados em aplicações técnicas por cada sociedade, sobretudo em seus preparos alimentares etc. (Lévi-Strauss ,1991):

Confrontado com condições técnicas e econômicas ligadas às características do meio ambiente natural, o espírito não fica passivo. Não reflete estas condições; reage a elas e articula-as logicamente em sistema. Não é tudo; porque o espírito não reage apenas ao meio ambiente que o rodeia, também tem consciência de que existem meios ambientes diferentes e de que os seus habitantes reagem a eles, cada povo à sua maneira.
Portanto, as culturas reagem de forma distinta ao ambiente que a rodeia, em que as escolhas de espécies de plantas e animais em um dado ambiente são arbitrárias. É o caráter arbitrário dessa escolha para composição dos mitos e ritos que fundamenta o predomínio da explicação estruturalista quanto ao ordenamento lógico do mito, cuja inspiração é a estrutura universal do espirito humano que remete finalmente à estrutura do mito, conforme suas palavras (Lévi-Strauss, 1986):

[...] escolhe certas espécies animais ou vegetais, certas substâncias minerais, certos corpos celestes e outros fenômenos naturais, para os dotar de uma significação e pôr em forma lógica um conjunto acabado de elementos. O estudo empírico condiciona $o$ acesso à estrutura.

Neste sentido, o mito é compreendido "como uma língua que tem por função significar a significação” (Lévi-Strauss, 1991).

Bateson (1987), embora não se filie ao estruturalismo, ao propor um novo campo de conhecimento, que ele denominou de ecologia da mente, adotou uma premissa que se aproxima do estruturalismo de Lévi-Strauss. Seu perfil interdisciplinar de biólogo e antropólogo ao mesmo tempo, dá a sua contribuição ao debate sobre as fronteiras uma conotação especialmente significativa, ao afirmar (Bateson, 1987): "As leis da conservação da energia pertencem mais a substância do que a forma. Mas o processo mental, ideias, comunicação, organização, diferenciação, padrão e etc. pertencem mais a forma do que a substância.” Ele propõe romper com a dicotomia que divide os fatos da vida e o padrão da ordem. Esta dimensão formal atribuída às atividades mentais está bem presente no pressuposto estruturalista, no qual o pensamento assume o caráter de uma linguagem estando submetido a certas estruturas mentais.

O problema epistemológico da relação entre cultura e natureza ganha novos contornos na antropologia francesa, no estruturalismo de Lévi-Strauss, especialmente em Mitológicas, obra complexa dedicada à formação de um inventário da mitologia indígena americana. Em torno desse estruturalismo serão analisados alguns desdobramentos produzidos por antropólogos como Castro (2002) e Descola (2007) através de suas pesquisas junto às populações indígenas da Amazônia, envolvendo estudos sobre o pensamento ameríndio.

Convém destacar que as divergências entre Descola e LéviStrauss, se encontram entre outras, em torno da distorção no conceito de ambiente em função da linguagem atribuída ao mito por Lévi-Strauss: "[ele] tendeu a tratar o ambiente como um léxico de propriedades, recomposto nos sistemas métricos, nos sistemas de classificação, nas produções ideológicas.” (Descola, 2007).

Assim, da crítica ao estruturalismo nasceu a proposta de uma antropologia da natureza por Descola, que se funda na rejeição da ideia de separação entre cultura e natureza para propor a ideia de que as relações entre elas são "contínuas e constantes de interação pessoal entre humanos e não-humanos através de todo tipo de dispositivos" (Campos e Daher, 2013). Como exemplo dessas formas de interação menciona os encantamentos e os sonhos em que se verificam comunicações no plano espiritual entre humanos e não humanos. Descola (2007) complementa que o ambiente visto assim seria tomado como um reservatório de elementos contrastivos, organizados em sistemas ideológicos, levando a estudos sobre transformações dentro do sistema.

Descola procura inovar ao investir no problema epistemológico da relação entre cultura e natureza através da tentativa de superar a clássica dicotomia entre eles, partindo da ideia formulada por Castro sobre o perspectivismo do pensamento ameríndio. O perspectivismo 
e o multinaturalismo, concebidos por Castro (2002) a partir do pensamento indígena e extraído de suas pesquisas na Amazônia, irá inspirar Descola em sua tentativa de desconstrução da dicotomia entre cultura e natureza.

O perspectivismo é assim definido por Castro (2002): "tratase da concepção, comum a muitos povos do continente, segundo a qual o mundo é habitado por diferentes espécies de sujeitos ou pessoas, humanas e não-humanas, que o apreendem segundo pontos de vista distintos." Esta apreensão mútua sob perspectivas diferentes se expressa em um plano cosmológico a partir da atividade da caça, em que animais predadores e espíritos se percebem como humanos e estes são identificados aos animais de presa no plano espiritual. É a relação de predador e presa que permite associar o contexto pragmático ao teórico constituindo a base da ontologia amazônica da predação (Castro, 2002).

Em suas pesquisas amazônicas Castro (2002) constatou no sistema de predação que nem todos os animais participam, mas apenas algumas espécies são selecionadas como predadores e outras como presas. Já Descola (2007) detectou a crença entre os Achuars da Amazônia equatoriana, de que não havia uma dissociação entre o mundo dos humanos e o dos não-humanos, baseada no fato de que a maioria das plantas e animais seriam dotados de alma, levando-o a uma retomada do animismo.

Descola insistindo na dissolução das fronteiras entre cultura e natureza, percebeu que não teria sucesso em sua tentativa de eliminar o dualismo entre natureza e cultura partindo da teoria do totemismo de Lévi-Strauss, uma vez que nela o dualismo é reafirmado. Desta forma, ele desqualifica o totemismo como sistema de classificação e propõe compreendê-lo através do animismo, o qual se fundamenta na noção de ontologia. Ao investigar a cosmologia indígena como referência empírica, ele propõe definir o coletivo segundo a sua perspectiva da antropologia da natureza: (Descola, 2007)

São todas as espécies que têm corpos semelhantes. [...] Os anímicos - [...] das minorias aborígenes da Malásia até a Amazônia - têm esta ideia de que o corpo é um invólucro de ferramentas biológicas que permite agir sobre o mundo e que, neste sentido, constitui a maneira pela qual cada espécie constrói seu mundo.

Castro (2002) e Descola (2007) partindo desta matriz cosmológica inserem no marco do debate epistemológico da antropologia da natureza, não só a tentativa de superação da dicotomia como modelo universal, mas propõem a inversão da dicotomia entre cultura e natureza, demonstrando que o modelo convencionalmente conhecido não é universal. É preciso deixar claro que o pressuposto da relação interespécies envolvendo humanos e não-humanos não é concebida numa perspectiva material das práticas econômicas e de subsistência em um nicho ecológico, mas no contexto do pensamento e da cosmologia ameríndia.

Para tratar da relação entre humanos e não-humanos, os autores citados recorreram à noção de coletivo de Latour (2004), porém extraindo sua dimensão política para inserir novamente o critério classificatório. Porém veremos que Latour formulou o conceito de coletivo para tratar de outra realidade como será demonstrado mais adiante.

\section{A Simetria na relaÇão Cultura E natureza ENTre a ANTROPOLOGIA DA NATUREZA E A ANTROPOLOGIA ECOLÓGICA} RENOVADA

Com Latour (2004) a antropologia da natureza constrói sua especificidade a partir da ênfase sobre o campo político da ciência em ação e das controvérsias entre os cientistas, como crítica à antropologia ecológica defendida por Ingold (2012). Esta vertente, ao contrário da anterior tem um diálogo mais estreito com as ciências naturais e particularmente com a ecologia humana, reconhecendo os aportes das pesquisas em bioantropologia e biosociologia. Com Ingold a antropologia ecológica se renova ao substituir a categoria dos humanos pela de vida como objeto de estudo antropológico.

$O$ debate entre esses dois autores revela o quanto ambas as abordagens teóricas trazem contribuições importantes para a antropologia para compreender as problemáticas do mundo contemporâneo, que envolvem não só os humanos, como os não humanos e que requerem uma visão interdisciplinar para abordar o mundo em colapso ou a vida em sua dinâmica.

Para abordar a simetria, Latour se remete ao legado da antropologia clássica por "tratar sem crise nem crítica o tecido sem costura das naturezas-culturas" (2007), ao assumir desde o inicio de sua trajetória a prática de produzir uma descrição do mundo com seus híbridos. Trata-se da habilidade de compor em uma mesma monografia elementos díspares que se conectam como ancestrais, cultivos de mandioca, ritos de iniciação etc. A comparação entre culturas diante de uma natureza universal produzia uma separação entre a cultura do nós, do antropólogo (ocidental) e a dos outros, do objeto de estudo (não ocidental), gerando uma nova proposta relativista de comparação do híbrido naturezas-culturas.

Desta maneira, Latour (2007) expande a divisão entre nós e eles para a dos humanos e não-humanos, considerando que ela se situa não apenas no centro do debate do relativismo como da própria ciência, já que tal divisão é uma construção ocidental, e não dos demais povos, chineses, ameríndios etc. A inserção do conceito de rede no debate em torno do local e do global permitiu estabelecer este fio ou as linhas que fazem a conexão entre eles: Para Latour (2007) "Os dois extremos, o local e o global, são menos interessantes do que as disposições intermediárias aqui chamadas de rede.”

Aliás, o conceito de rede confrontado ao de sistema entre outros que ganharam evidência nas abordagens ecológicas, revelou maior eficácia perante eles por seus atributos: "Mais flexível que a noção de sistema, mais histórica que a de estrutura, mais empírica que a de complexidade, a rede é o fio de Ariadne dessas histórias mescladas" (Latour, 2007).

Ainda que Latour tenha avançado muito na constituição do campo da antropologia da natureza, ao fazer o diálogo com Ingold emergem várias controvérsias em virtude da afinidade do antropólogo britânico com a antropologia ecológica e com a dimensão da ecologia da mente de Bateson (1987). Uma das controvérsias se manifesta através da crítica de Ingold (2012) a noção de rede de Latour (2007), propondo uma versão mais orgânica da rede através da ideia de teia ou trama.

Ao invés de rede, Ingold propõe: (2012) "um emaranhado de coisas, [...] num sentido preciso e literal: não uma rede de conexões, mas uma malha de linhas entrelaçadas de crescimento e movimento". Para retirar o foco dos objetos ou artefatos e técnicas se contrapondo a Latour, ele se interessa pelos processos vitais alimentados por fluxos materiais. Deste modo, sua noção de habitar o mundo pressupõe um ambiente sem objetos - ASO (Ingold, 2012) e constrói a concepção acerca da relação entre o ambiente e a condição de viver no mundo como: (Ingold 2013 p.12) "condição de estar vivo para o mundo, caracterizado por uma capacidade elevada de sentir e responder, na percepção e na ação, a um ambiente que está sempre em fluxo, que não permanece o mesmo de um momento para o outro.”

Contudo, para Latour (2006) na relação humanos e não humanos estão situados não apenas animais, vírus e bactérias como também, técnicas e instrumentos tecnológicos que passam a agir como um ator que provoca mudança em um dado cenário, onde ocorrem controvérsias frente a grupos que se reagrupam não para formar sociedade, mas coletivos. 
Convém chamar atenção para o fato de que as noções de rede e coletivos não incorporam as categorias de território e conflito (Little, 2002; 2006), centrais para a ecologia política que problematiza a relação entre cultura e natureza a partir das disputas em torno do acesso aos recursos naturais, gerando disputas por território. Trata-se de um enfoque que se mostra indispensável para tratar de realidades latinoamericanas e não apenas aquelas do contexto amazônico, abordadas por Descola e Castro. No âmbito deste trabalho a reflexão será feita a partir de comunidades indígenas nordestinas que vivenciaram um longo processo de aculturação, cujas cosmologias se mostram bem alteradas em relação às cosmologias amazônicas. Neste contexto as relações entre cultura e natureza sofreram novas mudanças, com a introdução de uma técnica de cultivo de camarão, que ameaça a sustentabilidade ambiental do estuário, onde eles habitam. Mas seguindo o prognóstico de Latour (2004) através das ações dos coletivos, porta vozes dos não humanos e daqueles formados em favor dos interesses dos humanos, reunidos em associações e fóruns, cuja consequência será a impossibilidade da manutenção da clássica divisão entre natureza e sociedade ou entre natureza e política.

\section{CULTURA E NATUREZA EM PESQUISA COM POPULAÇÕes LOCAIS: Os Potiguaras da aldeia de Tramataia-Marcação/PB}

As reflexões sobre as relações entre cultura e natureza a partir de agora serão baseadas em experiências concretas de mudanças vividas por uma população local, que foi alvo de uma pesquisa realizada nos dois últimos anos. A realidade selecionada é constituída por um grupo de indígenas da aldeia Potiguara de Tramataia no litoral norte da Paraíba, vivendo em seu próprio território em área semiurbana, cujas vivências com a natureza oferece um exemplo interessante de reflexão. A pergunta formulada em primeiro plano propõe indagar em que medida para o grupo pesquisado a relação entre cultura e natureza é material ou simbólica e em segundo plano como é possível manter o pressuposto da inseparabilidade entre cultura e natureza.

Trata-se de um povo indígena que possui vínculos históricos com o território em que vive desde a chegada dos portugueses, cujos laços com a terra são profundos e marcados por lutas travadas para permanecer em seu território, tendo conseguido garantir direitos fundiários com a demarcação e homologação de parte dessas terras a partir de 1991. Com isso, a construção da alteridade e etnicidade Potiguara é fruto da longa luta pela terra ainda em curso, que em tese propiciaria uma autonomia e isolamento. Contudo, os contatos ao longo dos séculos com a sociedade nacional levaram a uma aculturação lenta e gradual, no que tange a diversos aspectos da vida material, que alteraram igualmente a dimensão cosmológica. A economia tradicional Potiguara de pesca e agricultura já havia sido impactada desde o início do século passado com atividades de grande capital no seu entorno, como a fábrica têxtil de Rio Tinto que empregou população indígena e as plantações de cana de grandes usinas que penetrou nas terras indígenas e empregou mão-de-obra indígena.

A partir das duas últimas décadas um grupo de Potiguaras assimilou e implantou uma técnica de produção de camarões em viveiros em escala familiar em suas terras, que resultou em alguns danos ao ambiente natural formado por um manguezal em um estuário, inserido em uma área de proteção ambiental federal - APA da Barra do rio Mamanguape criada em 1993. A inovação técnica foi fruto de um lado, de uma demanda interna de indígenas insatisfeitos com o declínio da pesca, e motivados pelo sucesso da carcinicultura no vizinho estado potiguar, e do outro uma resposta institucional com apoio técnico e financeiro ${ }^{1}$ que possibilitou a implantação

1 A carcinicultura Potiguara foi viabilizada com recursos do Banco Mundial através do COOPERAR-PB em parceria com a Empresa Paraibana de desta inovação no sistema produtivo dos indígenas de Tramataia. O cultivo de camarão em viveiro foi introduzido na aldeia de Tramataia inicialmente através de um projeto da UFPB com camarão nativo, que não ofereceu resultado imediato levando os índios a buscarem a técnica com camarão exótico, já conhecido pela sua alta rentabilidade (Sampaio, 2015).

Sendo esta atividade dependente da compra de insumos adquiridos em empresas da região e a produção quase inteiramente voltada para o mercado, uma vez que ela se articula a uma rede que possui vários elos que estão fora do ambiente em que esta comunidade se insere.

A atividade de carcinicultura pressupõe a participação em uma rede que une camarões (espécie exótica), rações, antibióticos e indígenas carcinicultores ao mercado, integrado por empresas que fornecem os insumos da produção e compradores dos camarões destinados a restaurantes locais e da capital. Entre os elos da rede se desenvolvem relações intermediárias que revelam a singularidade do sistema, tendo em vista os arranjos construídos em que os intermediários ou compradores da produção são também indígenas, eliminando a figura dos atravessadores que fragilizam a condição dos produtores. Deste modo, são os compradores indígenas que realizam a venda para os restaurantes e mercados locais.

Este modelo permite uma forma de articulação da produção com o mercado, que reduz os conflitos existentes nas transações intermediadas por não indígenas, ao mesmo tempo em que incorpora um número maior de indígenas na cadeia produtiva do camarão, fortalecendo as relações entre eles.

A antropologia ecológica em certa medida está apta para examinar processos que ocorrem em um dado contexto ecológico, cujas interaçõesocorrem sobretudo naquele nicho. Contudo, uma mudança no modo de relação com a natureza ocorreu neste grupo de indígenas com a introdução de uma técnica de cultivo de camarões, que representou a substituição da atividade extrativista típica da pesca artesanal, praticada tradicionalmente por estes indígenas. A pesca artesanal significava um modo de relação com a natureza que dependia do conhecimento dos ciclos naturais das espécies e do tempo da natureza, uma vez que práticas extrativistas obedecem a esses ciclos. Já o cultivo de uma espécie exótica em viveiro, fora do habitat natural através de uma técnica que independe dos limites do tempo da natureza para seguir o tempo da produção, na qual o ciclo vital da espécie é reduzido em proveito da obtenção de maior produtividade e menor custo.

Embora a suposta significação etimológica da palavra 'potiguara' aluda à alcunha de povo comedor de camarão, a pesquisa revelou que os Potiguaras atuais não apreciam o camarão que cultivam e preferem o consumo de carne. Entre os indígenas atuais a preferencia pela carne pode sinalizar ora um status superior perante os demais indígenas não produtores de camarão, como também uma rejeição ao camarão cultivado, sendo o natural considerado mais saboroso e com mais prestígio.

Em entrevistas à pesquisa (Sampaio, 2015), os produtores potiguaras de camarão da aldeia de Tramataia disseram entender que o termo "melhoria da qualidade de vida" significa maior e melhor acesso à saúde, lazer, alimentação e moradia, o que foi incrementado após sua iniciação nos cultivos de camarões. Eles não entendem que a "autonomia sociocultural” signifique se manter nas antigas tradições, como a manutenção da dança do toré, da língua indígena e suas típicas moradias, mas consideram que cultivar, aprender e manter a atividade da criação de animais também vai terminar virando seu meio de vida e um dia também poderá se transformar em sua tradição (Sampaio, 2015).

Abastecimento e Serviços Agrícolas -EMPASA que forneceu os cursos de capacitação 
A avaliação do índio Potiguara carcinicultor entrevistado sobre um cenário futuro desta produção converge para a tese de Sahlins (1988) quanto a noção de modernização indígena, através da qual este processo supõe uma forma singular de apropriação de inovações do capitalismo globalizado pelos indígenas.

De fato, a criação de camarões em um meio artificial, ou seja, tanques escavados na parte terrestre do estuário com perda de manguezal é mediada pela intervenção humana através do uso de produtos químicos adicionados a rações e medicamentos para rápida engorda e combate de doenças. Com isso, o sistema elimina a cadeia alimentar natural, onde não há presas ou predadores concorrentes. A quebra deste ciclo natural entre predador e presa vai interferir ao mesmo tempo na dimensão simbólica do sistema cosmológico indígena, existente de modo operativo no modelo amazônico (Castro, 2002; Andrade, 2010).

Desta maneira, a cadeia produtiva possui um elo com um segmento externo não índio, que faz parte do sistema capitalista globalizado, ou seja, a empresa fornecedora de todos os insumos para o cultivo, começando pelas larvas do camarão. Com isso, no universo da carcinicultura familiar potiguara não há uma apropriação simbólica da natureza que possa ser traduzida em mitos e ritos, uma vez que o processo produtivo é artificial.

Por outro lado, é possível evocar outra realidade vivida por uma população local diante de impactos da modernização, reveladora da manutenção de vínculos afetivos e espirituais com a natureza. Esta realidade é vivenciada por um grupo de pescadores artesanais da praia de Suape, excluídos de sua área de pesca e das terras em que viviam, para dar lugar a grandes instalações portuárias e fabris (Santos e Andrade, 2013). Este grupo de pescadores artesanais mantém uma festa anual em torno do ouriço do mar, reveladora de laços afetivos com o mar através desta espécie, a partir da qual se desenha uma cosmologia. Esta festa se constitui como uma tradição inventada com pouco mais de sessenta anos que expressa de forma ritualizada e repleta de símbolos significativos a relação entre pescadores que perderam seu espaço de pesca, mas mantem uma apropriação simbólica do mar (Santos; Andrade 2013). A festa da ouriçada é iniciada pela coleta de ouriços do mar na linha de recifes naturais existente na praia, que ocorre apenas em um único dia do ano (o dia do marinheiro e de Santa Luzia), em período da reprodução dos ouriços em que eles se tornam abundantes. Neste dia dedicado ao ouriço a pesca habitual é proibida e culmina com uma distribuição coletiva da ouriçada, iguaria preparada pelas mulheres dos pescadores com o ouriço, verduras e farinha de mandioca, servida para os participantes do ritual. A festa é organizada por uma família de pescadores da praia de Suape, a qual se configura como uma expressão de resistência desta comunidade pesqueira, cuja atividade está prestes a desaparecer da área pelas pressões da gestão portuária (Santos e Andrade, 2013).

A escolha do ouriço como espécie alvo de ritualização e simbolização por esta comunidade pode ser entendida como supõe Lévi-Strauss como uma escolha arbitrária, uma vez que o ouriço não tem um valor de mercado já que não faz parte da alimentação habitual das comunidades locais ou da população regional. Por outro lado, o ouriço ganha visibilidade para o pescador por ser época de reprodução, representando o vínculo afetivo e de conhecimento do pescador com relação ao mar, de onde retirava seu sustento. Com a exclusão dos pescadores do seu território marítimo de pesca, os ouriços juntamente com a barreira natural de recifes da praia de Suape passam a representar simbolicamente os obstáculos à prática da pesca de alto mar realizada na zona posterior a barreira de recifes. Desta forma, o ouriço assume o papel de vítima em um ritual sacrificial, tornando-se comestível após a retirada da carapaça de espinhos, que representariam os obstáculos à pesca marítima para os pescadores artesanais. O prato da ouriçada constitui assim a oferenda de pescadores a protetores divinos da pesca, associados nesta comunidade a Santa Luzia protetora dos olhos.

Outro fator que contribui para a quebra nos vínculos entre cultura e natureza presentes em cosmologias indígenas, entre os Potiguaras, consiste no confronto com a legislação ambiental que incide sobre a porção do território indígena que se encontra em sobreposição com a área de proteção ambiental. O discurso ambiental dominante tem contribuído para fortalecer a noção de separação entre cultura e natureza, através de controles e leis que restringem fortemente as atividades das populações locais/tradicionais que vivem nestas áreas, cujas práticas tornam-se criminalizadas. O discurso da separação entre cultura e natureza é reforçado através da insistência na ideia da necessidade de eliminação das atividades exercidas pelas populações locais, ou do abandono de suas práticas tradicionais. A atividade considerada compatível com a proteção pelos órgãos ambientais tem sido a do turismo de natureza e de contemplação, que igualmente rompe com um modo de vida mais sintonizado com os ciclos da natureza. Considerando, o caso específico desta sobreposição de APA e Terra Indígena, o confronto é maior tendo em vista a adoção de uma prática não tradicional (a carcinicultura) que provoca impactos no estuário.

Contudo, a produção comunitária ou familiar de camarão em viveiro, apesar de provocar menos impactos, em função da escala da produção ser menor - menos de 5\% da área da APA Barra do Rio Mamanguape é utilizada pelos carcinicultores indígenas (Sampaio apud ICMbio, 2015), para os órgãos ambientais, os impactos são considerados graves.

Sampaio (2014) em seu levantamento dos impactos ambientais da carcinicultura indígena destacou os seguintes: supressão de parte do mangue para a construção de seus viveiros; proximidade de grande parte deles da margem do estuário do rio Mamanguape; escape da espécie exótica cultivada quando as comportas de despesca e/ou os taludes desabam; má qualidade da construção dos viveiros; e falta de apoio técnico adequado no cultivo para controle de doenças e mortandade dos camarões contaminando a área.

Já para os indígenas pescadores artesanais a carcinicultura não teria provocado impacto sobre a pesca, uma vez que o declínio da pesca teria sido causado pelos danos da atividade agrícola das usinas, iniciado décadas antes, com o plantio de cana e uso de agrotóxicos arrastados para as águas do estuário. A situação singular da carcinicultura indígena contradiz a literatura que revela fortes conflitos entre grandes empreendimentos de carcinicultura e populações locais e movimentos ambientalistas em defesa dos manguezais desde a década de 1990 em Equador, Colómbia e Honduras (Alier, 2009). Contudo, no caso desta população local, os conflitos ambientais se manifestam entre pescadores indígenas $\mathrm{e}$ usineiros, se configurando como conflitos distributivos identificados pela ecologia política (Alier, 2009)

Já os especialistas em análise ambiental irão compor um coletivo dominado por gestores de agencias ambientais que assumem o papel de porta-voz da natureza, em confronto com o coletivo indígena e gestores de agencias de apoio ao indígena, que defendem direitos culturais de autonomia sobre suas terras. Deste modo, a problemática da economia indígena atual se aproxima das disputas entre os coletivos como aponta Latour (2004).

\section{CONSIDERAÇões FinaIS}

Com o trajeto analítico feito em torno do debate sobre as fronteiras entre cultura e natureza com base nas abordagens antropológicas selecionadas, buscou-se refletir a respeito das 
fronteiras e possibilidades de diálogo entre o saber antropológico e o saber ambiental. Este questionamento resultaria das querelas em torno da superação da dicotomia entre natureza e cultura, tendo em vista o crescente envolvimento da sociedade em defesa da conservação da natureza, em virtude dela depender a própria sobrevivência da humanidade.

A crítica ao antropocentrismo, construída no âmbito do pensamento ecológico e do ambientalismo, ao atribuir aos humanos a responsabilidade pela crise ambiental, seja através da racionalidade capitalista, ou ideologias ocidentais incluindo o cristianismo, provocou uma reflexão antropológica a cerca desta crítica. Latour (2004) e Ingold (1995) oferecem algumas pistas, ao abordar a relação entre humanos e não humanos ou humanidade e animalidade, relativizando a soberania dos humanos.

Desta maneira, o pensamento antropológico mais recente retira os humanos do centro do debate para situá-lo em redes técnicas em interação com não humanos ou teias orgânicas, em que o mundo local das populações tradicionais está interligado por diferentes tramas ao mundo global.

Com a introdução da prática do cultivo de camarão entre os Potiguaras, a relação entre cultura e natureza assume uma conotação material e utilitária, com a perda de vínculos existentes nas práticas extrativas tradicionais, em que um novo saber técnico ainda que precário vem desorganizar o saber local/tradicional ou provocar uma desaprendizagem do conhecimento anterior como adverte Santos (2010).

As interações cada vez mais intensas dos Potiguaras com a sociedade envolvente gera uma assimilação da modernização, e de uma lógica capitalista em suas atividades, em que se constata um processo de "modernização" e globalização que afeta as comunidades indígenas. Segundo Sahlins (1988), esta modernidade pode ser incorporada à tradição, mesmo que no primeiro momento esta incorporação seja confusa, pois, ao ser melhor observada é capaz de revelar a história dela.

E se a pesca artesanal permitia a vivência no estuário em uma relação não apenas material como simbólica com a natureza, dando lugar a uma memória onde personagens míticos protetores da natureza, como o "pai do mangue", que exprimem uma relação afetiva e de respeito frente ao mundo natural (Silva, 2011). Esta dependeria de uma compreensão dos ciclos naturais, que é desarticulada neste sistema de cultivo, cuja produção é destinada não para o consumo, mas para o mercado.

No confronto entre as novas abordagens antropológicas que apontam a superação da ruptura entre cultura e natureza e as pesquisas etnográficas recentes sobre populações locais/tradicionais sob a influência da economia globalizada, observa-se a perda dos antigos vínculos entre cultura e natureza. No caso investigado esta perda deveu-se a criação de camarão em viveiro, que modificou a relação dos índios com o estuário e o manguezal substituindo a atividade extrativa de caranguejo e demais espécies existentes na área. Com o novo sistema produtivo, a relação com a natureza se modifica para ser tratada como recurso, e dependendo da escala da exploração do recurso os danos provocados ao ambiente podem ser irreversíveis.

Ao longo de quase duas décadas dessa inovação tecnológica na economia indígena houve problemas de mercado com a desvalorização no preço, bem como técnicos com a proliferação de doenças, gerando a queda na produção e no número de viveiros em atividade (Sampaio ,2015). Com isso, a atividade vem se ajustando a uma escala menor e a um modelo familiar, facilitando com isso negociações com o órgão de controle, de modo a se adequar a dimensões que favoreçam a sua sustentabilidade socioambiental.

Assim, esta realidade pode mudar conforme Sahlins (1988), já que a cultura indígena não está desaparecendo por estar cada vez mais incorporando a lógica não-indígena, mas sim, se transformando e, tornando-se mais complexa em sua diversidade. Ela implica ainda uma reinvenção no modo de habitar este ambiente que se encontra em curso, de modo a fundir os interesses da natureza ligados à conservação da biodiversidade com interesses indígenas que assegurem a manutenção da sociodiversidade.

\section{REFERÊNCIAS}

Adams, C. 2000. Caiçaras na mata atlântica: pesquisa científica versus planejamento e gestão ambiental. São Paulo: Annablume.

Andrade, M.O.; Lima, G.F. (Orgs.) 2012. Gestão e Desenvolvimento Socioambiental na Paraíba: Concepções e Práticas. Vol.1. João Pessoa: Ed. Universitária da UFPB.

Andrade, M.O., 2010. A dimensão simbólica e espiritual da biodiversidade nas cosmologias indígenas e abordagens filosóficas. in: Horizonte, Belo Horizonte: Puc Minas vol.8, nº17, p. 11-25, abr/ jun.

Bateson, G. 1987. Steps to an ecology of mind. New Jersey/ London: Jason Aronson Inc. 1987.

Campos, R.; Daher, A. 2013. Entrevista - A antropologia da Natureza de Phillipe Descola. Topoi (Rio J.) vol.14 no.27 Rio de Janeiro July/ Dec.

Castro, E. V. 2002. Perspectivismo e multinaturalismo na América indígena in: A inconstância da alma selvagem, São Paulo: Cosac y Naify, p. 345-399.

Descola, P. 2007 . À propos de Par-delà nature et culture in: Tracés, Revue des Sciences Humaines, nº12, p. 231-257.

Diamond, J. 2012. Colapso, como as sociedades escolhem o fracasso ou o sucesso. Rio de Janeiro: Record.

Foladori, G. e Taks, J. 2004. Um olhar antropológico sobre a questão ambiental in: Mana n 10 (2) p.323-348.

Harris, M. 2011. Vacas, cerdos, guerras y brujas. Madrid: Alianza editorial.

Ingold, T. 1995. Humanidade e animalidade. Revista Brasileira de Ciências Sociais, 28, junho.

Ingold, T. 2012. Trazendo as coisas de volta à vida: Emaranhados criativos num mundo de materiais. Horizontes Antropológicos, Porto Alegre, ano 18, n. 37, p. 25-44, jan./jun.

Ingold, T. 2013. Repensando o animado, reanimando o pensamento, Espaço Ameríndio, Porto Alegre, v.7, n.2, p.10-25, jul./dez.

Latour, B. 2004. Políticas da natureza: Como fazer ciência na democracia. Bauru-SP: EDUSC.

Latour, B. 2006. Como prosseguir a tarefa de delinear associações?, in Configurações, $n^{\circ}$ 2, p. 11-27.

Latour, B. 2007. Nunca fuimos modernos: ensayo de antropologia simétrica. Buenos Aires: Siglo Veintiuno Eds.

Lévi-Strauss, C. 1991. O cru e o cozido. Mitológicas. São Paulo: Brasiliense.

Lévi-Strauss, C. 1986, O meio ambiente e suas representações in: O olhar distanciado. Lisboa: Edições 70, p.148-173. 
Lévi-Strauss, C. e Eribon, D. 2005. De perto e de longe. São Paulo: Cosac y Naify.

Little, P. 2002. Territórios sociais e povos tradicionais no Brasil: por uma antropologia da territorialidade. Série Antropologia, n³22, Brasília.

Little, P. 2006, Ecologia Política como etnografia: um guia teórico e metodológico, in: Horizontes Antropológicos, n 25, p.85-103, Porto Alegre: PPGAS.

Martinez-Alier, J. 2009. O Ecologismo dos Pobres: conflitos ambientais e linguagens de valoração. São Paulo: Contexto.

Neves, W.A.1996. Antropologia Ecológica: um olhar materialista sobre as sociedades humanas. São Paulo: Cortez.

Rappaport, R.A. 1984.Pigs for the ancestors: ritual in the ecology of a New Guinean People. New Haven:Yale University Press.

Sahlins, M. 1978, A primeira sociedade de afluência in: CARVALHO, E. (org) Antropologia Econômica, São Paulo: Livraria Editora de Ciências Humans. p.7-44.
Sahlins, M. 1979. Cultura e Razão Prática, Rio de Janeiro: Zahar.

Sahlins, M. 1988, Cosmologias do Capitalismo: O SetorTrans-Pacífico do 'Sistema Mundial. In: Anais da XVI Reunião Brasileira de Antropologia. Campinas-SP, pp. 47-106.

Sampaio, J. A.A. 2015. A carcinicultura familiar na aldeia indígena Potiguara de Tramataia, Marcação/Paraíba: em busca da sustentabilidade. Dissertação Programa de PósGraduação em Desenvolvimento e Meio Ambiente - PRODEMA/ UFPB.

Santos, B. S.; 2010. Pensamento Abissal: linhas globais da ecologia dos saberes. in Santos, B. S.; Menezes, M. P. (orgs) Epistemologias do Sul. São Paulo: Cortez.

Santos, J. O.; Andrade, M. O. 2013. Festa da Ouriçada e devoção a Santa Luzia na praia de Suape-PE: expressão sincrética e simbólica da biodiversidade e do território de pescadores artesanais. Horizonte, Puc Minas. Vol. 11, n 30.

Silva, R. E. 2011. Sob o olhar do Pai do Mangue: ensaio sociológico sobre a relação homem-natureza mediada por uma narrativa mítica. João Pessoa: Ideia. 